\title{
Research On Maritime College basic math reform In Teaching System
}

\author{
Yongxiang Li, Peirong Ge
}

Marine college of Shandong jiaotong university, Weihai, Shandong,China

Keywords: University math teaching; Teaching mode; Teaching chain; teaching reform

\begin{abstract}
Higher mathematics as a basis for various disciplines of science and engineering education at the University, has incomparable reach and impact than the other disciplines. especially as connected with related subjects, infiltration, of higher education has become a top priority. Mathematics is an important basic courses for college students majoring in navigation, strengthen the research on the teaching reform of basic math, for the best sailing talents come to the fore to provide better protection. Maritime College mathematics teaching reform in the basic courses are still in the exploratory stage, there is no comprehensive study on mathematics Foundation courses combine effectively with maritime characteristics needs, in maritime institutes under the new situation is an important study on the teaching reform of work.
\end{abstract}

\section{Introduction}

Mathematics is an important basic courses for college students majoring in navigation, mathematics courses, not only so that students ' knowledge structure can be expanded and provide services as a professional course of study, is more important to cultivate the students ' creative thinking ability, abstract, logical reasoning, learning ability, problem analysis and problem-solving skills, are helping to improve students ' comprehensive quality. The current rapid development of maritime education and maritime colleges nationwide 12, sailing 24 in high vocational college, Shandong province has 19 maritime institutes and training agencies, and college entrance examination students in Shandong province, has been down for 5 consecutive years, increasingly fierce competition among the institutions and, therefore, develop internationally competitive high-quality expertise in navigation becomes critical.

Maritime College math courses including advanced mathematics, linear algebra, probability theory and mathematical statistics, and it is the core part of the advanced mathematics, advanced mathematics is to learn physics, theoretical mechanics and material mechanics, fluid mechanics, electrician Foundation, sailing an important foundation for math courses and tools. Used modern mathematics of views, and thought and method reform teaching content and courses system, full consider this, and specialist students and navigation, and turbine, professional of different needs, more used module teaching, timely added professional courses needed of mathematics content, as on specialist students added plural, and vector, content, on undergraduate students strengthening calculus, and differential equation, content of explained, effective do mathematics based courses and professional courses of effective convergence, for students follow-up learning in the may of needs or interest training better to provides based knowledge, Help students to improve their capacity for life-long learning.

In mathematics course of teaching process in the, more used modern of teaching means, according to teaching content of different, used explains more practice, class discussion, job comments, variety form for teaching, desalination operation skills, enlightenment students of innovation consciousness, in play teachers led role of while, full play students of subject role, respect students personality specialist of play, especially for excellent navigation class talent of stand out created favourable conditions. 


\section{Analysis of the present situation of mathematics teaching in maritime institutes}

With the deepening of teaching reform, College mathematics reform has made certain achievements, from the national to the teaching reform of colleges and universities set up different levels of the project, members of College mathematics teaching objectives, curricula, teaching methods, and an in-depth exploration of the teaching mode of reform, but still not perfect. College basic math teaching process, the author constantly exchanges and discussion with the students and the teacher, found that there are still many problems in College mathematics teaching.

A. Teaching content lacking, it is difficult to combine with professional

I often have students ask during the teaching process: learn what use is higher mathematics? College mathematics so many classes have to do with our professional relationship? Indeed, many old University College Mathematics syllabus, teaching school as all professional and uniform, not combined with the student's professional, not really their aptitude. Teachers ' lack of communication with the teachers of basic courses, students ' expertise did not understand, it is difficult to combine with professional.

B. Theory of teaching content, the lack of innovative consciousness

On the teaching contents of theoretical and computational mathematics at the University, and fewer applications, textbooks boring, lack of novelty. Due to the influence of examination-oriented education idea, too much emphasis in the teaching of mathematical logic, rigorous, systematic and theoretical, and large proportion of teaching math skills, or even simply excessive demands on the operation skills. Due to time constraints, examination results-oriented reasons, teachers teaching most of the energy in the mathematical logic proofs and calculation method of teaching, making late-classical theory has a strong engineering background and application from the insufficient emphasis on the cultivation of students ' ability, so that students feel boring and of no practical use of mathematics, it is difficult to interest.

C. Old teaching methods, test methods

Blackboard-oriented teaching method of basic and derived in detail on the Blackboard teacher problem-solving process, the lack of interaction with students, help students to receive knowledge in a completely passive, rather than take the initiative to learn. Examination is also relatively simple, basically followed "a paper examination paper quality" approach, neglected to examine students ' learning processes, and solve practical problems so that students lose confidence in math, College Math intimidates and University math courses up to fail students each year.

\section{Maritime approaches to mathematics teaching reform in colleges}

A. Optimization of curriculum structure, which combined with the professional demands

Without changing the system of mathematics of the University based on the optimization of teaching contents and teaching methods, focusing on practice teaching, teaching students not only to be the problem, but also to understand the background of mathematical concepts, development, familiar with knowledge of practical background and links with other disciplines. Professional features into account when introducing mathematical concepts, improving application consciousness of the students in the classroom teaching.

Works closely with the maritime relationship between some of the mathematical concepts, such as derivative, integral, potential energy, power series, mathematical statistics, and introduced them with professional practice, students learn to use mathematics and cultivating students ' interest in mathematics. For example, the navigation majors requires students to master the knowledge of data mining. Data mining is a study from a large number of incomplete and noisy, fuzzy stochastic process of extracting useful information and knowledge, is a professional advanced undergraduate and graduate courses. About data mining can actually in probability theory and statistics this course be infiltration. In the course of probability theory and mathematical statistics, traditional teaching with emphasis on probability, mathematical statistics tell little.

Now, based on the cultivation of students ' ability to solve practical problems, and should focus 
on mathematical statistics teaching contents, lay the Foundation for later learning data mining. Teachers can arrange time, Sas, Spss and other statistical software to students, which for complex numerical calculations in the mathematical statistics, can be overcome. As another example, in the rapid development of computer, in operations research linear algebra, cryptography, computer graphics, virtual reality, and so has a wider application, many students are interested in this aspect of, and therefore can be targeted in the process of teaching introduction to linear algebra applications in this regard, enhance students ' interest in learning.

B. Teaching strategies to improve

(1) teaching

Problem type teaching formed by a series of questions and solve the problem. starting from the main one leads to the related issue is the basic ideas of classroom teaching. from special to General questions, programme or from the general problem of the optimal design.

(2) level teaching

Multi-level teaching is reflected in teaching materials, teaching methods, testing, and other aspects to achieve teacher's "knowledge of supply" and the student "knowledge demand curve" in the best fitted. textbook levels decided by the Professional category. Select different categories of materials to meet the needs of different professional categories of talents in higher mathematics.

(3) direct-teaching

Intuitive type method has been was high mathematics education by praised, key is enhanced students of image thinking capacity, inspired students of learning interest, also mathematics to really. many mathematics problem from actual, and problem of solution and can better to guide actual. just for mathematics symbol transform, logic reasoning, not thinking mathematics of actual background, mathematics of learning will will boring and difficult to application Yu actual. so, high mathematics teaching process in the focused on thinking training is is important of a ring.

4) heuristic method of teaching

Elicitation method of teaching allows students to have thinking time, supporting students ' multiple perspectives, different ways of thinking, give full play to their imagination, to get more programmes or the best program to solve the problem.

C. Additional mathematics elective courses and mathematics experiment course

Teach basic math mentioned above should strengthen the training of mathematical modeling. But because of time restrictions, this mathematical modeling activity is limited, some students wanted to further study. So do well in mathematics courses at the same time, multidisciplinary mathematics elective courses, such as mathematical modeling, cryptography, linear programming, enriching the content of mathematics teaching. The other hand, students ' characteristics of setting up mathematics experimental class, introducing Matlab,Mathematica, Sas and other mathematical software, such as seeking limits, derivatives, and integrals, solution of equations, are available through software such as paint or further use of the software on mathematical models. By mathematical experiment can combine mathematics and computers, some practical problems of mathematics, applied mathematics-related software for digital simulations, mathematical modeling and other aspects of training to improve students ' ability to analyze and solve problems. Meanwhile, to enhance collaboration and teamwork, improving innovation ability, laying the Foundation for future scientific research.

D. Improving teaching methods

Teachers should change completely the Blackboard "traditional"-style teaching methods, use of multimedia and writing methods, lengthy definitions, theorems or complex abstraction of the graphics can be used directly, such as the multimedia show, teachers have more time and energy to talk about its background and content. Multimedia teaching can visualize the abstract concept of boring. For example talking about higher mathematics when the structure is in the domain of convergence of power series, first introduced Abelian theorem, reflect the region of convergence of the power series is at the origin as the center of the range. If you use the Blackboard teaching several axis you can only draw on the Blackboard explanation of connotation of the theorem, the student was not impressed. 
Using multimedia with two funny little numbers on the run in the direction from the origin to two, go through all the convergence point, up to a certain point, and then after all is the point of divergence. This dynamic process is images, enable students to learn the theorem is very excited, very fun, so students in a relaxed atmosphere to remember the content of the theorem, and until now, this theorem, the students immediately said: "there are two villains running,......" remember very clearly. When learning geometry, some graphics with writing on the Blackboard is unable to accurately draw, multimedia is very convenient to use. Visible the proper multimedia use in teaching, you can make teaching a multiplier effect.

E. Change the way of examination

With the change of teaching content, teaching methods, assessment should be done in the way of reform. Formerly unified written test examination in the school into "theory + practical applications written examination abilities" pattern, test should be carried out in professional. Final results is divided into usually results and exam results, usually results to job, and attendance as main according to, will final exam content and students of professional phase combined, teachers design exam topics, let students play by learn of mathematics thought and method to solution professional in the of problem, such can inspired students of innovation thinking, exercise its understanding capacity and calculation capacity, on students of learning situation made a just of evaluation.

University core curriculum reform is a long-term project, there are still many problems to be solved, we need from the teaching practice of the course, combining full and professional needs, deepen the teaching reform, improve students ' interest in mathematics, and enhance students ' University mathematics theory and its application in engineering and innovation.

\section{References}

[1] Wang Haixia, Sun Hejun, Wang Qingyun. Thoughts of improving the teaching of linear algebra methods [j]. Study of advanced mathematics, 2010, 13 (6): 13-15

[2] Xu Lizhi. views on the reform of mathematics education and mathematics and construction [j]. Journal of Mathematics Education, 2000,9 (2):.

[3] Chen Longan. creative thinking and the teaching of [m]. Beijing: China light industry publishing house, 1999.

[4] Liu Yinping. discussion on creative thinking in College mathematics teaching mode [j]. University, 2003,19 (5).

[5] Zhang Dianzhou. reform of College Mathematics Department vision [j]. Journal of Mathematics Education, 1999. (l)

[6] Jiang qiyuan, Xie Jinxing, ye Jun. mathematical modeling, third edition, 2003.8.

[7] Chen zonghai. process system modeling and simulation. University of science and technology of China Press, 2009.

[8] Sun Chang. modeling and simulation of ship handling system. Wuhan University of technology master degree thesis. 2003:4

[9] Jia Xinle, Dr halophytic. mathematical model of ship movement mechanism and identification modeling. Dalian Maritime University Press, 2007 